\title{
Pore structure and the properties of electric double layer capacitor electrode of bamboo-derived activated carbon prepared by superheated steam
}

\author{
Keisuke Kikuchi ${ }^{1} \cdot$ Rie Yamashita $^{2} \cdot$ Satoshi Sakuragawa ${ }^{2} \cdot$ Keigo Hasumi $^{3} \cdot$ Yasuhiro Mukai $^{3} \cdot$ Hiroya Kobayakawa $^{3}$. \\ Shojiro Wakabayashi ${ }^{3} \cdot$ Yukie Saito $^{4}$
}

Received: 6 November 2017 / Accepted: 14 May 2018 / Published online: 13 June 2018

(c) The Japan Wood Research Society 2018

\begin{abstract}
Bamboo-derived activated carbon prepared by superheated steam (BAC) exhibited performance for utilization as an electric double layer capacitor (EDLC) electrode. Pore structure and EDLC performances were investigated by comparison with phenol resin-derived activated carbon (MSP-20), which is commercially available and often used for the purpose. The nitrogen adsorption isotherm showed that BAC had a large BET-specific surface area of $1268 \mathrm{~g} / \mathrm{m}^{2}$ with a developed pore structure, especially of the mesopore, in comparison with MSP-20. It is considered that inherent ash in bamboo promoted activation, in addition to physical activation by superheated steam. Capacitance per electrode volume $\left(C_{\mathrm{V}}\right)$ was $52 \mathrm{~F} / \mathrm{cm}^{3}$ with BAC. Because the density of BAC is high $\left(0.78 \mathrm{~g} / \mathrm{cm}^{3}\right)$ compared with that of MSP-20 $\left(0.58 \mathrm{~g} / \mathrm{cm}^{3}\right)$, sufficient $C_{\mathrm{V}}$ for usage was obtained, although the capacitance per electrode mass $\left(C_{\mathrm{M}}\right)$ at $5 \mathrm{~mA} / \mathrm{cm}^{2}$ itself of BAC $(67 \mathrm{~F} / \mathrm{g})$ was lower than that of MSP-20 (126 F/g). With IR drop, the resistance value of BAC $(9.7 \Omega)$ was lower than that of MSP-20 $(10.5 \Omega)$. Especially, the diffusion resistance of BAC disclosed to be smaller than that of MSP-20. These results indicated that BAC produced by steam activation is a promising material with a pore structure suitable for ion transfer in EDLC.
\end{abstract}

Keywords Bamboo $\cdot$ Activated carbon $\cdot$ Steam activation $\cdot$ Electric double layer capacitor

\section{Introduction}

Activated carbon (AC) is one of the important adsorbents for industrial usage and its high performance has been used for the purification of gases and liquids. Recently, AC was revealed to be applicable for electrodes of an electric double layer capacitor (EDLC) and many studies have been reported on it. Most carbon materials for industrial devices

Keisuke Kikuchi

k.kikuchi@iri.pref.shizuoka.jp

1 Hamamatsu Technical Support Center, Industrial Research Institute of Shizuoka Prefecture, 1-3-3 Shinmiyakoda, Kita-ku, Hamamatsu 431-2103, Japan

2 Industrial Research Institute of Shizuoka Prefecture, 2078 Makigaya, Aoi-ku, Shizuoka 421-1298, Japan

3 SUNCALL CORPORATION, 14 Umezunishiuracho, Ukyo-ku, Kyoto 615-8555, Japan

4 Graduate School of Agriculture and Life Sciences, The University of Tokyo, 1-1-1 Yayoi, Bunkyo-ku, Tokyo 113-8657, Japan are produced from synthetic polymers or by products originating from fossil resources such as petrol and coal. AC production from biomass is focused on the shift from monopole dependence on fossil resources to multipole use, including sustainable biomass resources. Besides coconut shells, which have been historically required to produce $\mathrm{AC}$ with a high specific surface area (SSA), cocoons [1], pruned apple branches [2], wheat bran, and spent coffee grounds (SCG) [3] were reported as potential raw materials for high-quality AC. Recently, bamboo has also attracted attention [4-9], especially because of its fast growth and sustainable yield.

A capacitor, traditionally known as an electric condenser, is used in electronic circuits to block direct current while allowing alternating current to pass, smoothing the output of power supplies, and stabilizing the voltage and power. The property of energy storage in capacitors is focused on. EDLCs are electrochemical capacitors whose energy storage is achieved by double layer capacitance, which appears at the boundary between a conductive electrode and an adjacent liquid electrolyte. Because the ions transfer charge, SSA and the surface structure of electrodes play an important role in 
EDLC performance: SSA directly determines the amount of ion adsorption, and the pore structure influences ion mobility. Thus, AC is adequate for EDLC, satisfying not only its electron conductivity, but also providing a highly developed SSA of $1000 \mathrm{~m}^{2} / \mathrm{g}$ or more. The large SSA is due to fine pores formed on its surface. Additionally, the performance of EDLC requires pore structure allowing ions to easily diffuse inside and facilitating rapid charge-discharge behavior. Many studies aiming to improve the pore structure of $\mathrm{AC}$ for EDLC have been carried out, and it was revealed that a mesopore, corresponding to a pore with a diameter of 2-50 nm, can satisfy this purpose.

Activation is an important process to produce a large SSA together with an adequate pore structure upon raw carbon material. There are two types of activation methods. One is chemical activation. Among chemical activations, the method using potassium hydroxide is thought to be the most effective for obtaining a large SSA, and many studies of $\mathrm{KOH}$ activation have been carried out [10-13]. Bamboo AC having a large SSA of $1400 \mathrm{~m}^{2} / \mathrm{g}$ was achieved by $\mathrm{KOH}$ activation [14]. However, $\mathrm{KOH}$ activation needs a large amount of $\mathrm{KOH}$ (approximately three or four times the mass of the raw material carbon), requiring prudent assembly of the apparatus to avoid corrosion [3]. The other one is gas activation. It is simple and easy, without the need for any dangerous chemicals and complicated washing processes for resultant AC. Among gas activations, steam activation is frequently used because only water is needed as an activation regent and so it is economical $[4,15,16]$. However, steam activation is less effective for producing a large SSA compared with $\mathrm{KOH}$ activation.

By achieving steam activation of bamboo char, we aimed to combine the effects of gas and chemical activations. In general, some plant biomass naturally includes potassium as an ash component, which can cause chemical activation. When a simple steam activation for plant biomass is carried out, $\mathrm{KOH}$ activation due to the naturally included ash can be simultaneously expected and the effects of activation should be double. So far, we have carried out steam activation using SCG [17], and found that composted SCG show the additional effects of ash activation, because the potassium content increased during fermentation, and mesoporerich AC appropriate for EDLC was produced [18]. Organic components such as fat are consumed by fermentation but ash amount does not change. As a result, the ash was concentrated and the ratio increased. In the case of bamboo, ca. $1 \mathrm{wt} \%$ of ash is included, and the main component $(80-90 \mathrm{wt} \%)$ of the ash is potassium $[19,20]$. Thus, the additional activation effects by naturally included potassium are expected via simple steam activation. Currently, the invasion of farm land by bamboo is a serious problem in the south of Japan, and a method to use such bamboo has been urgently sought. Trials of bamboo use for AC production by a simple and environmentally friendly method will also satisfy social requirements.

In this study, we produced BAC (bamboo-derived activated carbon prepared by superheated steam), and investigated the EDLC performance together with the pore structure. The temperature in the furnace can be raised efficiently using superheated steam together with heater because steam has a higher heat transfer rate than air. To evaluate the EDLC performance of resultant samples, we sometimes face the problem of inconsistencies in the previous literature, for example, specimen preparation, measurement conditions, and the way of calculating capacitance vary without any standards. To overcome this problem, a commercially activated carbon, often used as a reference in EDLC studies, was applied for comparison, and the EDLC performance and surface structure of BAC were investigated.

\section{Experiment}

\section{Sample}

Culms of bamboo, Phyllostachys pubescens Mazel ex Houzeau de Lehaie, which were grown in Miyazu, Kyoto, aged 3 years or older, were harvested from June through November 2014 and dried in air. They were cut into chips with a diameter of a few $\mathrm{mm}$. The ash content of the dried raw bamboo was measured by heat treatment at $850{ }^{\circ} \mathrm{C}$ for $1 \mathrm{~h}$ in air.

\section{Carbonization and activation with superheated steam}

A total of $300 \mathrm{~g}$ of bamboo chips, whose moisture content was $10.3 \mathrm{wt} \%$, were spread thinly in a specimen holder of a carbonization/activation furnace (Fig. 1). The samples were sequentially heated by an increase of $70{ }^{\circ} \mathrm{C} / \mathrm{min}$ and held at $250{ }^{\circ} \mathrm{C}$ for $30 \mathrm{~min}$, by an increase of $83{ }^{\circ} \mathrm{C} / \mathrm{min}$ and held at $500{ }^{\circ} \mathrm{C}$ for $20 \mathrm{~min}$, by an increase of $43{ }^{\circ} \mathrm{C} /$ min and held at $930^{\circ} \mathrm{C}$ for $240 \mathrm{~min}$, and finally returned to room temperature, taking about $4 \mathrm{~h}$. When the temperature reached $250{ }^{\circ} \mathrm{C}$, steam produced at $100{ }^{\circ} \mathrm{C}$ under $0.2 \mathrm{MPa}$ by a steam-generator (NBC-2070R, NAOMOTO INDUSTRY CO., LTD.) was introduced from the top of the furnace (Fig. 1). The treatment schedule of carbonization/activation is indicated in Fig. 2. The schedule was not fixed but provisional. The yield was calculated by dividing the weight of BAC by the weight of untreated bamboo that had been completely dried.

Prior to measurement of the pore structure and electrode performance, BAC was washed in nitric acid to remove naturally included ash and thoroughly rinsed in de-ionized water until achieving a neutral $\mathrm{pH}$. 


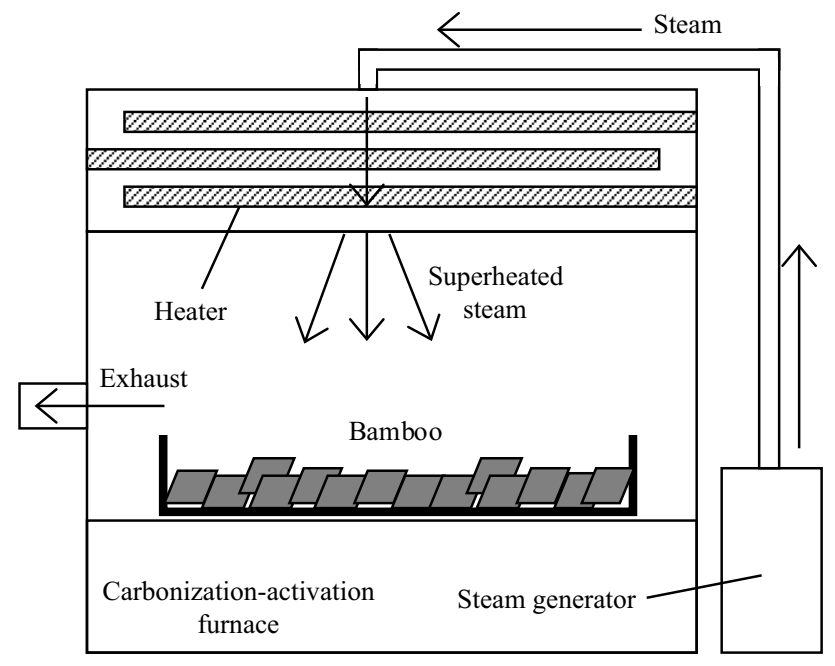

Fig. 1 Schematic of the carbonization/activation furnace

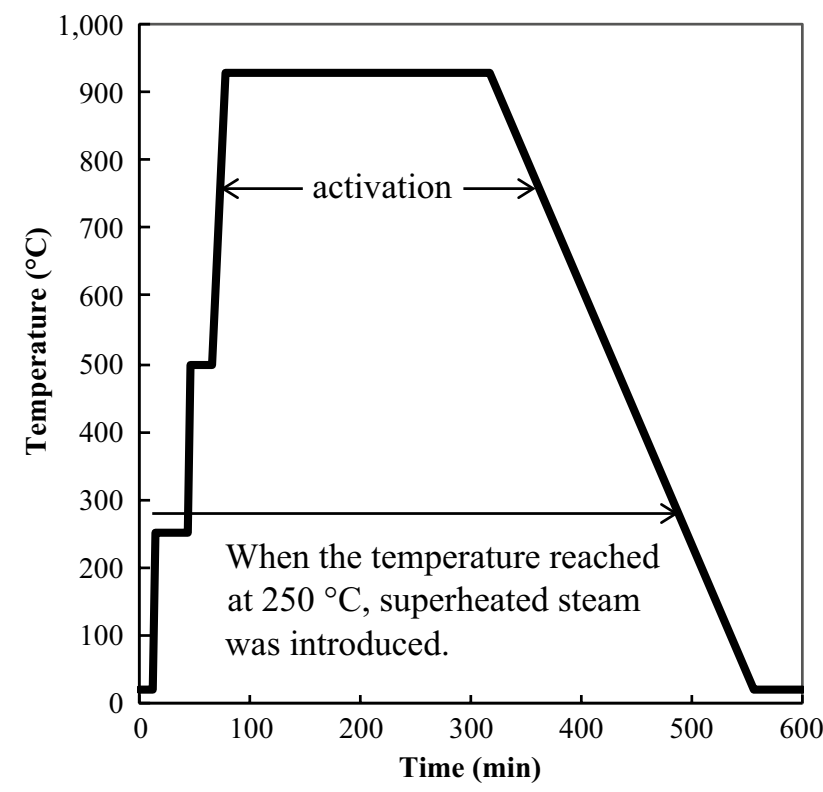

Fig. 2 The temperature and time of carbonization/activation

Commercial phenol resin-derived AC (MSP-20, Kansai Coke and Chemicals Co., Ltd.), which is often used in EDLC studies, was applied for the comparison of properties described below with the samples produced by bamboo.

\section{Analysis of the pore structure}

The acid-washed BAC was pulverized by Multi-Beads Shocker (MB1000, Yasui Kikai Corporation) and measured to assess the particle size distribution (LA-950, HORIBA, Ltd.). Nitrogen isotherms were obtained (BELSORPmax, MicrotracBEL Corp.) and the BET theory [21] with the multi-point method, HK [22], and BJH [23] methods were applied to determine SSA and pore size distributions, respectively.

\section{Preparation of EDLC electrode and investigation of its performance}

Electrodes were prepared by mixing $80 \mathrm{wt} \%$ activated carbon, $10 \mathrm{wt} \%$ carbon black and $10 \mathrm{wt} \%$ polytetrafluoroethylene (PTFE), together with a small amount of ethanol. The mixed paste was rolled out into a sheet $100 \mu \mathrm{m}$ thick using a tabletop roll press machine (HSMNRP-1, Hohsen Corp.) and cut into a circular electrode form of approximately $2 \mathrm{~cm}^{2}$. The electrode was heated in a vacuum at $250{ }^{\circ} \mathrm{C}$ and then the weight and thicknesses were precisely measured. It was immersed in an electrolyte solution of $1 \mathrm{M}$ triethylmethylammonium tetrafluoroborate (TEMA-BF4)/propylene carbonate (PC): transfusing the electrolyte into fine pores of the electrodes and assembling the bipolar electrode as a cointype cell (HS cell, Hohsen Corp.) were carried out in a glove box. A charge-discharge cycle (CC) under constant current was measured at $30^{\circ} \mathrm{C}$, in a voltage range of $0-2.5 \mathrm{~V}$, at current densities of $5,10,15,25,50$, or $75 \mathrm{~mA} / \mathrm{cm}^{2}$, using an electrochemical measurement system (HZ-7000, HOKUTO DENKO CORP). Capacitance was determined from the slope of the discharge curve between $1 \mathrm{~s}$ after discharging had started and the moment of full discharge. The IR drop value was measured at $1 \mathrm{~s}$ after the discharge of constant current, under a constant voltage of $2.5 \mathrm{~V}$. Impedance measurement between the frequency range of $10 \mathrm{mHz}-100 \mathrm{kHz}$ was conducted under full discharge. Resistance components of EDLC in a Nyquist plot were calculated according to a previous report [13].

\section{Results and discussion}

The yield of BAC before removing ash was $5.8 \mathrm{wt} \%$. Figure 3 shows that the particle size distribution of pulverized BAC and MSP-20 are quite similar. It has been reported that the resistance value of EDLC can decrease under the influence of a decreasing particle size [24]. However, in this case, the difference in particle size was negligible (Fig. 3). Thus, only the effects of the pore structure will be discussed in the following part to compare the EDLC performances of these samples.

Nitrogen adsorption isotherms of both BAC and MSP20 exhibited a type I isotherm based on the IUPAC classification (Fig. 4). The initial rise of the plot is less steep with BAC than MSP-20. This means that the micropore structure is less developed with BAC than MSP-20. The micropore distribution of BAC appears in a smaller area at a peak of $0.44 \mathrm{~nm}$ than that of MSP-20 at $0.54 \mathrm{~nm}$, while the 


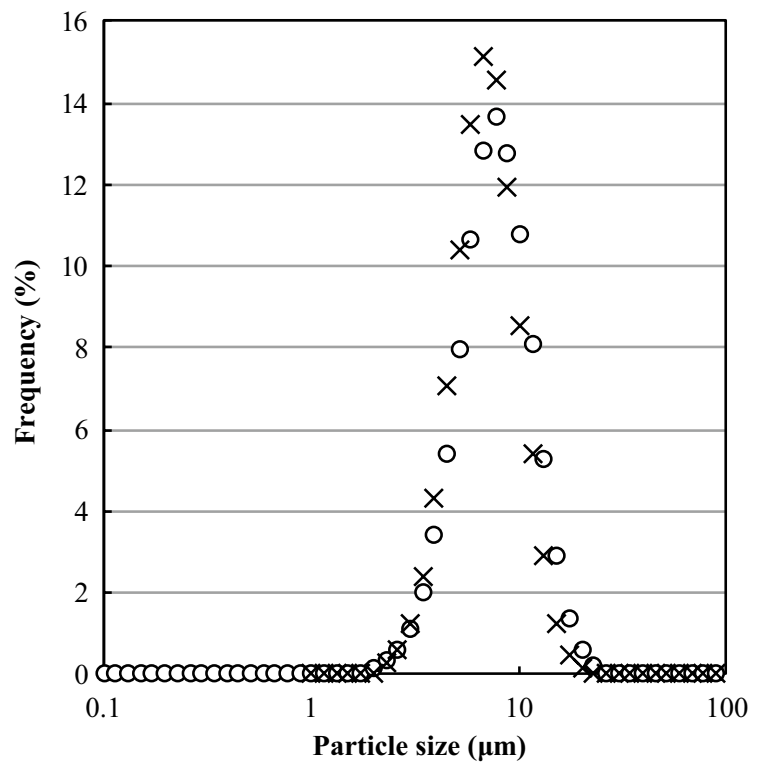

Fig. 3 Particle size distribution of activated carbon. Circle: BAC (bamboo-derived activated carbon prepared by superheated steam). Cross: MSP-20 (commercial phenol resin-derived activated carbon)

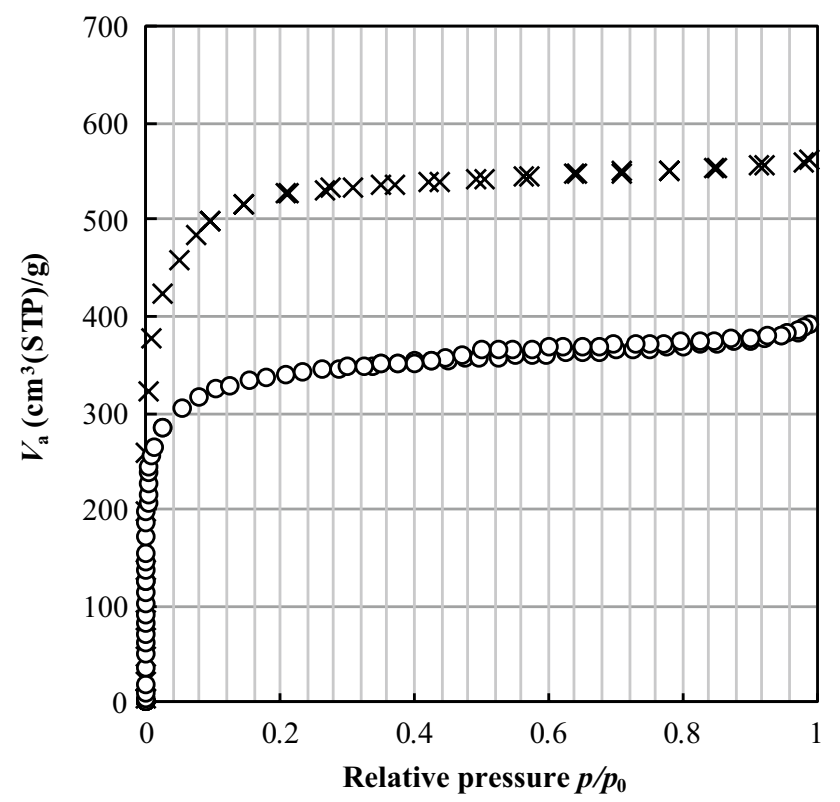

Fig. 4 Nitrogen adsorption isotherm for each activated carbon. Circle: BAC (bamboo-derived activated carbon prepared by superheated steam). Cross: MSP-20 (commercial phenol resin-derived activated carbon)

intensity of BAC was lower than that of MSP-20 (Fig. 5). This indicates that the micropores of BAC are less developed than those of MSP-20, although the pore size of BAC is ca. $0.1 \mathrm{~nm}$ smaller than that of MSP-20. According to $\mathrm{BJH}$ analysis, BAC had a more developed mesopore structure than MSP-20 (Fig. 6). SSA of BAC was quite high,

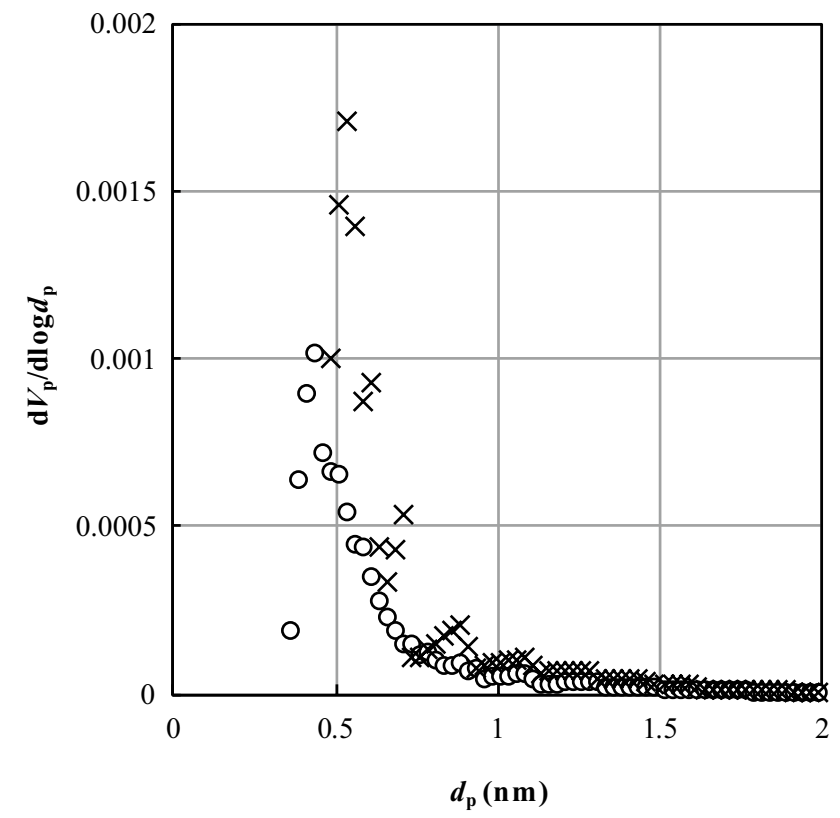

Fig. 5 Micropore distributions obtained using the HK method from the nitrogen adsorption isotherm. Circle: BAC (bamboo-derived activated carbon prepared by superheated steam). Cross: MSP-20 (commercial phenol resin-derived activated carbon)

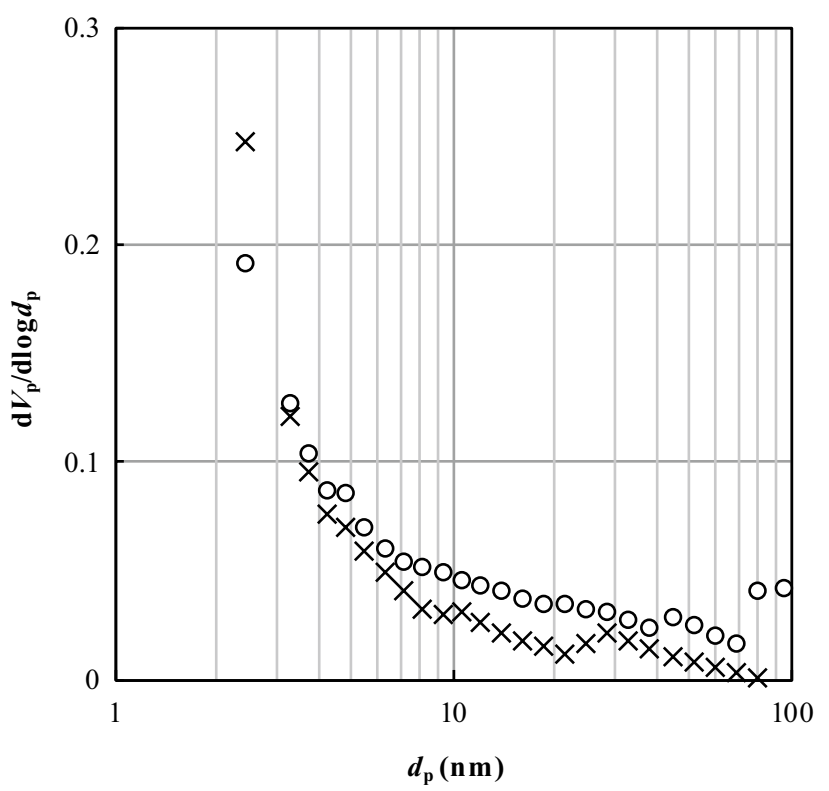

Fig. 6 Mesopore distributions obtained using the BJH method from the nitrogen adsorption isotherm. Circle: BAC (bamboo-derived activated carbon prepared by superheated steam). Cross: MSP-20 (commercial phenol resin-derived activated carbon)

at $1268 \mathrm{~m}^{2} / \mathrm{g}$, although it is still lower than that of MSP$20\left(2010 \mathrm{~m}^{2} / \mathrm{g}\right)$. The moderately high SSA value of BAC is thought to be attributed to the developed micro and mesopore structures formed on the surface of BAC. At least 
two possible mechanisms could be the cause of mesopores in carbon materials [25]. One involves the mesopore originating from the parent raw materials. It has been reported that bamboo charcoals, especially from $P$. pubescens, are relatively rich in mesopores [5]. The other involves those newly developed by the fusion of some micropores through the activation process. In our case, BAC exhibited mesopores with a diameter of approximately $2-50 \mathrm{~nm}$ of $0.11 \mathrm{~cm}^{3} / \mathrm{g}$, whereas bamboo carbonized at $900{ }^{\circ} \mathrm{C}$ showed $0.03 \mathrm{~cm}^{3} / \mathrm{g}$. Considering these data, the original mesopores before activation are negligible in comparison with those derived with activation. It has been reported that mesopores of charcoal derived from pruned apple branches were developed by activation due to the catalytic reaction of naturally included ash [26]. A similar phenomenon is expected in our study with bamboo including an ash content of $0.9 \mathrm{wt} \%$, bringing additional activation effects to gas activation to produce a mesopore-rich structure, which has the merit of promoting EDLC performance of rapid charge/discharge by enabling the easy adsorption/desorption of ions [27]. Total specific surface area $\left(S_{\text {total }}\right)$, micropore specific surface area $\left(S_{\text {micro }}\right)$, external specific surface area $\left(S_{\text {ext }}\right)$ calculated from t-plot and the percentage of $S_{\text {ext }}$ to $S_{\text {total }}\left(R_{\text {ext }}\right)$ are shown in Table 1. BAC indicated a higher $R_{\text {ext }}$ than MSP-20. This means that well-balanced pore structure of relatively large pore and micropore was formed in BAC.

The values related to properties as electrodes are listed in Table 2. The assembled electrode for measurement had a higher density of $0.78 \mathrm{~g} / \mathrm{cm}^{3}$ with BAC, than that of $0.58 \mathrm{~g} /$ $\mathrm{cm}^{3}$ with MSP-20. The values were affected by the original densities of the activated carbon samples, because the composition for electrode assembly was the same for both samples. The high-density value of BAC suggests a strong potential as an electrode. The density of BAC is thought to be sufficiently tolerable for further activation, leading to the further development of SSA. Figure 7 shows the capacitance per electrode mass $C_{\mathrm{M}}(\mathrm{F} / \mathrm{g})$ obtained by CC tests. MSP-20 showed a high $C_{\mathrm{M}}$ of $120 \mathrm{~F} / \mathrm{g}$ or more, at $5 \mathrm{~mA} / \mathrm{cm}^{2}$, but the value decreased with an increase in the current density, and the $C_{\mathrm{M}}$ was no longer countable at $50 \mathrm{~mA} / \mathrm{cm}^{2}$ or more. On the other hand, BAC showed $C_{\mathrm{M}}$ with more favorable retention and further availability at a higher current density than

Table 1 Pore structure properties calculated from t-plot

\begin{tabular}{lllll}
\hline Sample & $S_{\text {total }}\left(\mathrm{m}^{2} / \mathrm{g}\right)$ & $S_{\text {micro }}\left(\mathrm{m}^{2} / \mathrm{g}\right)$ & $S_{\text {ext }}\left(\mathrm{m}^{2} / \mathrm{g}\right)$ & $R_{\text {ext }}(\%)$ \\
\hline BAC & 1400 & 1358 & 42 & 3.0 \\
MSP-20 & 2132 & 2106 & 26 & 1.2 \\
\hline
\end{tabular}

$B A C$ bamboo-derived activated carbon prepared by superheated steam, MSP-20 commercial phenol resin-derived activated carbon, $S_{\text {total }}$ total specific surface area, $S_{\text {micro }}$ Micropore specific surface area, $S_{\text {micro }}=S_{\text {total }}-S_{\text {ext }}$, $S_{\text {ext }}$ external specific surface area, $R_{e x t}$ the percentage of $S_{\text {ext }}$ to $S_{\text {total }}$
MSP-20, although the $C_{\mathrm{M}}$ value itself was lower than that of MSP-20. Capacitance retention ratios are shown in Fig. 8. BAC indicated a higher retention ratio than MSP-20. It was considered that $\mathrm{BAC}$ had a high $R_{\text {ext }}$, which enabled ions to access to the surface of BAC easily and the capacitance retention ratio got higher. Capacitance per BET-specific surface area of BAC and MSP-20 were 53 and $63 \mathrm{mF} / \mathrm{m}^{2}$, respectively. The value of BAC was smaller than MSP-20. We infer that BAC has some area which cannot be used effectively since its micropore was very small compared to MSP-20 as shown in Fig. 5.

Figure 9 shows the capacitance per electrode volume $C_{\mathrm{V}}$ $\left(\mathrm{F} / \mathrm{cm}^{3}\right)$ obtained by multiplying $C_{\mathrm{M}}$ by the electrode density. BAC $C_{\mathrm{M}}$ is half that of MSP-20 $C_{\mathrm{M}}$ (Fig. 7). The differences

Table 2 Physical properties of electrodes prepared from each activated carbon

\begin{tabular}{lllll}
\hline Sample & $\begin{array}{l}\text { Mass } \\
(\mathrm{mg})\end{array}$ & $\begin{array}{l}\text { Thickness } \\
(\mu \mathrm{m})\end{array}$ & $\begin{array}{l}\text { Density } \\
\left(\mathrm{g} / \mathrm{cm}^{3}\right)\end{array}$ & $\begin{array}{l}\text { Average density } \\
\left(\mathrm{g} / \mathrm{cm}^{3}\right)\end{array}$ \\
\hline BAC & 15.35 & 100 & 0.768 & 0.78 \\
& 15.65 & 101 & 0.775 & \\
& 16.20 & 103 & 0.786 & \\
MSP-20 & 12.55 & 108 & 0.581 & 0.58 \\
& 12.60 & 107 & 0.589 & \\
\hline
\end{tabular}

$B A C$ bamboo-derived activated carbon prepared by superheated steam, MSP-20 commercial phenol resin-derived activated carbon

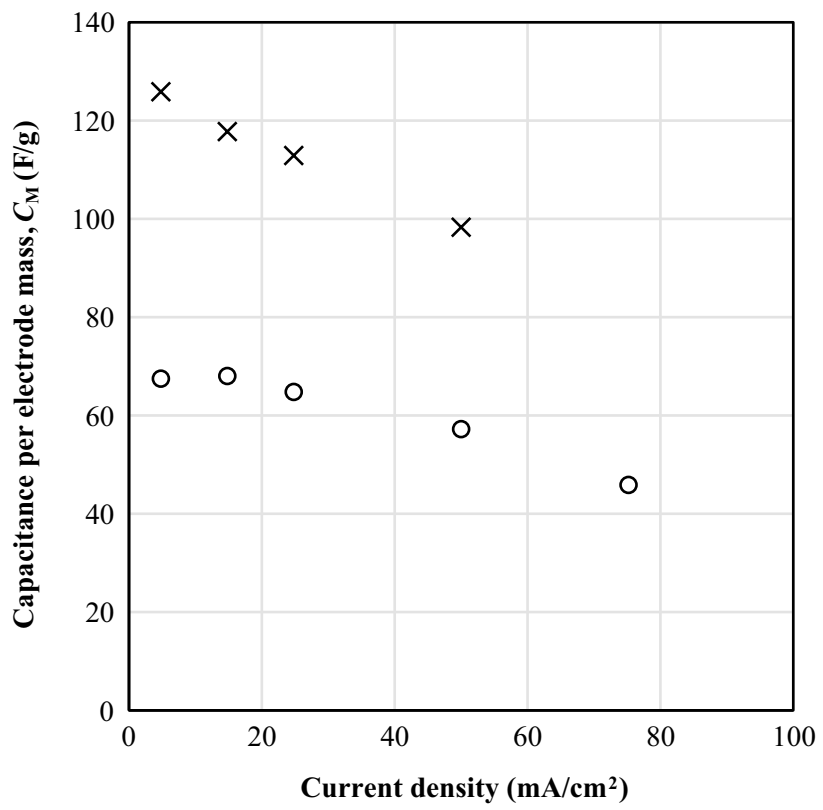

Fig. 7 Capacitance per electrode mass $\left(C_{\mathrm{M}}\right)$ against current density. Circle: BAC (bamboo-derived activated carbon prepared by superheated steam). Cross: MSP-20 (commercial phenol resin-derived activated carbon) 


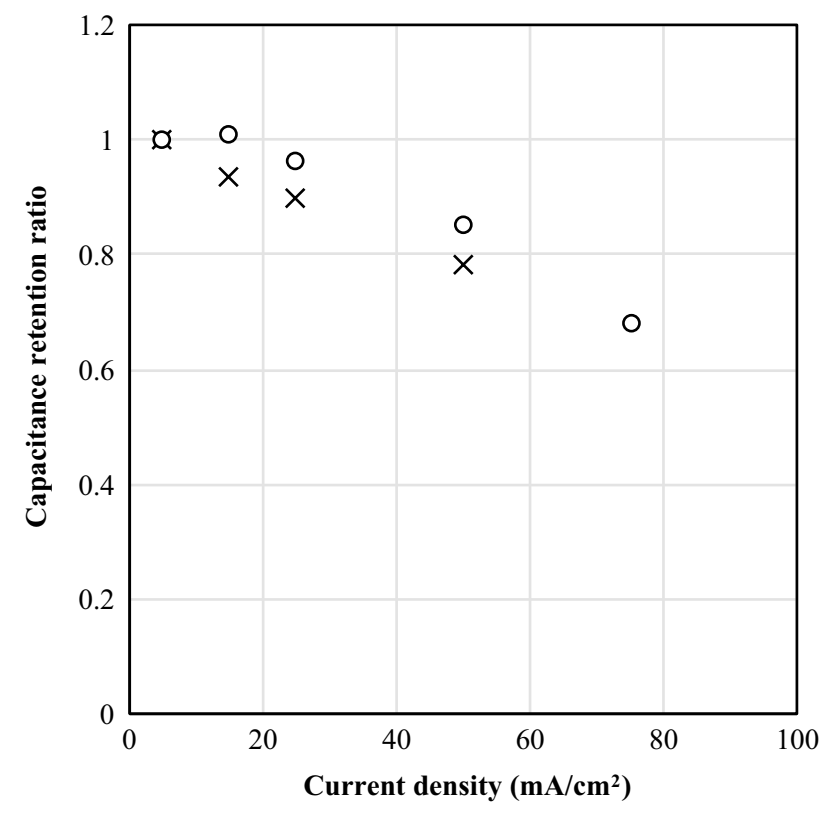

Fig. 8 Capacitance retention ratio against current density. Circle: BAC (bamboo-derived activated carbon prepared by superheated steam). Cross: MSP-20 (commercial phenol resin-derived activated carbon)

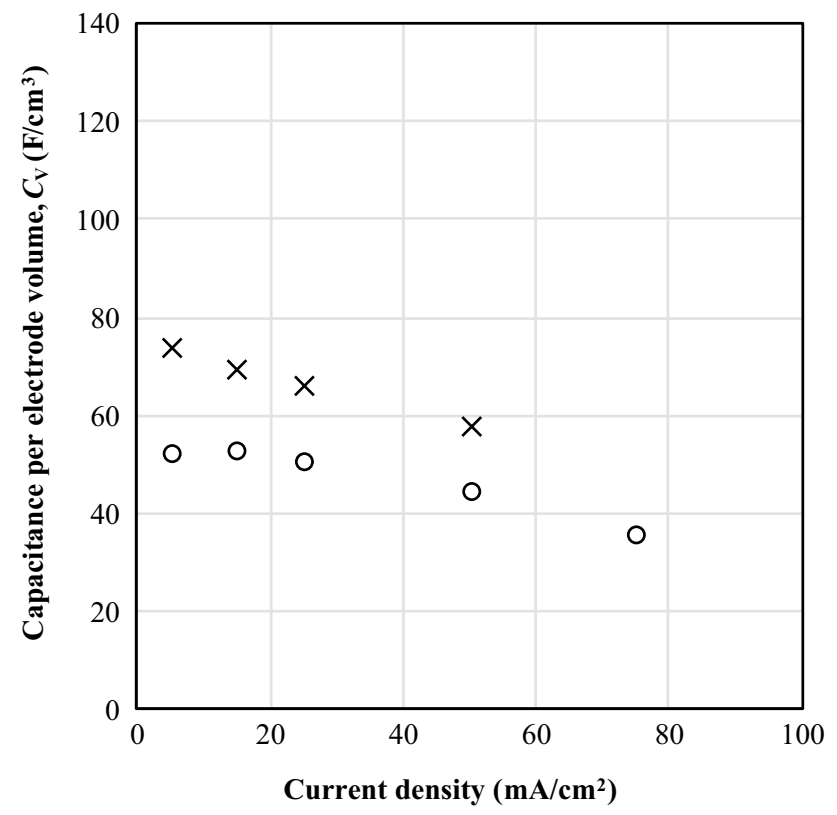

Fig. 9 Capacitance per electrode volume $\left(C_{\mathrm{V}}\right)$ against current density. Circle: BAC (bamboo-derived activated carbon prepared by superheated steam). Cross: MSP-20 (commercial phenol resin-derived activated carbon) in $C_{\mathrm{V}}$ are much smaller, with BAC $C_{\mathrm{V}}$ approaching ca. $80 \%$ of MSP-20 $C_{\mathrm{V}}$. This is because $C_{\mathrm{V}}$ is a function of electrode density; the electrode density of BAC is higher than MSP20. $C_{\mathrm{V}}$ is an important index for automobiles and electronic devices; a capacitor with a high $C_{\mathrm{V}}$ has the merit of being able to be installed in a small space.

On the basis of IR drop, BAC had a lower resistance value of $9.7 \Omega$ than MSP-20 (10.5 $\Omega$ ). Figure 10 shows a Nyquist plot obtained from impedance measurement. Resistance components of EDLC can be divided into three: (1) bulk resistance, corresponding to the value between $(0,0)$ to the starting point of the plot, (2) contact resistance, appearing as a hemicircle, and (3) diffusion resistance, appearing as a diagonal line with a slope of $45^{\circ}$. The calculated values of the components are summarized in Table 3. All types of resistance are lower with BAC than with MSP-20, but the difference was clear with diffusion resistance, which is related to ease of ion transfer in and out of pores. The reason for the low diffusion resistance of BAC may be the development of a mesopore structure.

\section{Conclusions}

An electrode of EDLC was produced from bamboo by simple steam activation.

BAC had a micropore-rich structure similar to that of MSP-20, however, BAC was revealed to be a more mesopore-rich structure than MSP-20. It can be explained that inherent ash would act as catalyst to promote steam activation.

$C_{\mathrm{V}}$ of BAC was as high as $52 \mathrm{~F} / \mathrm{cm}^{3}$, being sufficient for industrial usage, although it is smaller than that of MSP-20, $74 \mathrm{~F} / \mathrm{cm}^{3}$. In addition, BAC showed a capacitance retention ratio against the current density superior to MSP-20, probably because BAC had a developed mesopore structure for the easier transfer of ions than MSP-20. The resistance value calculated from the IR drop was smaller with BAC $(9.7 \Omega)$ than MSP-20 (10.5 $\Omega$ ). Impedance measurement revealed that, especially, the diffusion resistance of BAC was smaller than that of MSP-20.

It was concluded that $\mathrm{BAC}$ is a promising raw material for electrodes of EDLC, with a suitable pore structure for ion transfer. 

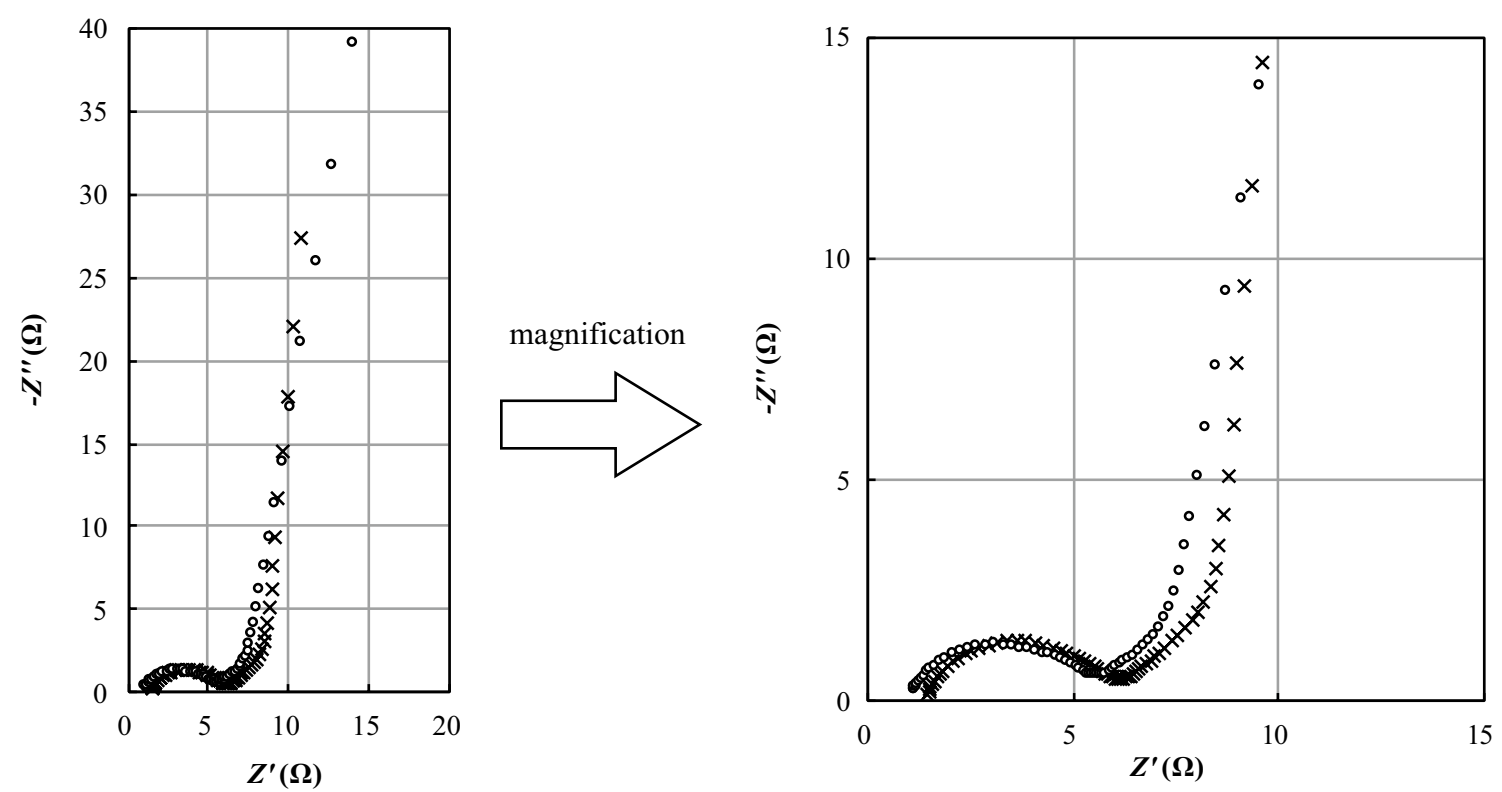

Fig. 10 Nyquist plot obtained from impedance measurement. Circle: BAC (bamboo-derived activated carbon prepared by superheated steam). Cross: MSP-20 (commercial phenol resin-derived activated carbon)

Table 3 Each resistance component value estimated from a Nyquist plot

\begin{tabular}{lllll}
\hline Sample & $\begin{array}{l}\text { Bulk } \\
\text { resistance }\end{array}$ & $\begin{array}{l}\text { Interface } \\
\text { resistance }\end{array}$ & $\begin{array}{l}\text { Diffusion } \\
\text { resistance }\end{array}$ & Total \\
\hline BAC & 1.1 & 4.5 & 1.8 & 7.4 \\
MSP-20 & 1.5 & 4.7 & 2.4 & 8.5 \\
\hline
\end{tabular}

Unit: $\Omega$

$B A C$ bamboo-derived activated carbon prepared by superheated steam, MSP-20 commercial phenol resin-derived activated carbon

\section{References}

1. Kojima A, Ogawa T, Fujishige M, Kamiishi Y (2007) Preparation of activated carbons from cocoon (in Japanese). J Silk Sci Tech Jpn 16:39-44

2. Hirose T, Kushibiki M (2011) Effect of activated temperature on characteristics of activated carbon from pruned apple branches (in Japanese). Mokuzai Gakkaishi 57:136-142

3. Hayashi J, Muroyama K, Yabuno M, Otani T (2000) Preparation of activated carbon from food waste by chemical activation with $\mathrm{K}_{2} \mathrm{CO}_{3}$ (in Japanese). Environ Sci 13:632-635

4. Abe I, Iwasaki S, Asami K, Senda J (2003) Preparation of activated carbon from bamboo (Phyllostachys pubescens Mazel ex Houzeau de Lehaie) by carbonization and activation with steam, carbon dioxide, or air (in Japanese). TANSO 208:114-119

5. Abe I, Hasegawa T, Shibutani Y, Iwasaki S (2004) Pore structural properties of bamboo charcoals (in Japanese). TANSO 215:241-245

6. Iwasaki S, Hasegawa T, Ohya K, Shibutani Y, Abe I (2005) Effect of shape and size of raw material in preparation of microporous carbon materials from bamboo (Phyllostachys pubescens Mazel ex Houzeau de Lehaie) (in Japanese). TANSO 220:270-275

7. Liu Q, Zheng T, Wang P, Guo L (2010) Preparation and characterization of activated carbon from bamboo by microwaveinduced phosphoric acid activation. Ind Crops Prod 31:233-238

8. Ahmad AA, Hameed HB (2010) Effect of preparation condition of activated carbon from waste for real textile wastewater. J Hazard Mater 173:487-493

9. Wang L (2012) Application of activated carbon derived from 'waste' bamboo culms for the adsorption of azo disperse dye: kinetic, equilibrium and thermodynamic studies. J Environ Manag 102:79-87

10. Wu Y, Jin XJ, Zhang J (2013) Characteristics of nitrogen-enriched activated carbon prepared from waste medium density fiberboard by potassium hydroxide. J Wood Sci 59:133-140

11. Dobashi A, Shu Y, Hasegawa T, Maruyama J, Iwasaki S, Shen Y, Uyama H (2015) Preparation of activated carbon by KOH activation from amygdalus pedunculata shell and its application for electric double-layer capacitor. Electrochemistry 83:351-353

12. Kikuchi K, Yamashita R, Sakuragawa S (2012) Effects of activation with $\mathrm{CO}_{2} / \mathrm{KOH}$ on the pore structures of coffee groundsderived carbon. Trans Mat Res Soc Jpn 37:557-562

13. Kikuchi K, Yasue T, Yamashita R, Sakuragawa S, Sudoh M, Itagaki M (2013) Double layer properties of spent coffee groundsderived carbon activated with potassium hydroxide $(\mathrm{KOH})$. Electrochemistry 81:828-832

14. Kim Y, Lee B, Suezaki H, Chino T, Abe Y, Yanagiura T, Park CK, Endo M (2006) Preparation and characterization of bamboo-based activated carbons as electrode materials for electric double layer capacitors. Carbon 44:1581-1616

15. Ito E, Sano T, Kouchi I, Okuda M, Nakano T, Umemura M, Niwa Y, Yashio M, Azuma Y, Yamaji Y, Toyoda M, Inagaki M (2007) Preparation of porous carbons from cypress using super-heated steam. I. Carbonization furnace and its characteristics (in Japanese). TANSO 229:249-254

16. Ito E, Yokoi T, Inagaki M (2007) Preparation of porous carbons from cypress using super-heated steam. II. Pore structure of carbonized products (in Japanese). TANSO 229:255-260 
17. Kikuchi K, Yasue T, Yamashita R, Sakuragawa S, Sudoh M, Itagaki M (2013) Electric double layer capacitor using spent coffee grounds-derived activated carbon prepared by steam activation. In: Proceedings of 11th international conference on ecomaterials, pp 55-58

18. Kikuchi K, Yamashita R, Sakuragawa S, Saeki T, Oikawa K, Kume T (2017) Pore structure and chemical composition of activated carbon derived from composted spent coffee grounds. TANSO 278:118-122

19. Wakisaka H, Miyake H, Kawahara Y (2006) Preparation of activated carbon from bamboo (Phyllostachys heterocycla) and influence of potassium fraction on activation process (in Japanese). TANSO 224:272-275

20. Yamashita N, Machida M, Aikawa M, Tatsumoto H (2009) Preparation of porous bamboo carbon by low-temperature activation in air (in Japanese). Mokuzai Gakkaishi 55:299-304

21. Brunauer S, Emmett HP, Teller E (1938) Adsorption of gases in multimolecular layers. J Am Chem Soc 60:309-319
22. Horvath G, Kawazoe K (1983) Method for the calculation of effective pore size distribution in molecular sieve carbon. J Chem Eng Jpn 16:470-475

23. Barrett PE, Joyner GL, Halenda PP (1951) The determination of pore volume and area distributions in porous substances. I. computations from nitrogen isotherm. J Am Chem Soc 73:373-380

24. Kouzu M, Haba E, Takei K (2008) High performance activated carbon for electric double layer capacitor (in Japanese). Hitachi Chem Tech Rep 51:13-16

25. Marsh H, Rodríguez-Reinoso F, Kawashita Y (2011) Activated carbon translated by Hayashi M, Kawashita Y (in Japanese). Maruzen Publishing, Tokyo, pp 220-223

26. Hirose T, Kikuchi T, Kushibiki M (2012) Properties of acidwashed activated carbon from pruned apple branches (in Japanese). Mokuzai Gakkaishi 58:63-68

27. Wang L, Inagaki M, Toyoda M (2009) Contributions of micropores and mesopores in electrode carbon to electric double layer capacitance (in Japanese). TANSO 240:230-238 